\title{
Percepções de jornalistas brasileiros sobre privacidade $\mathrm{a}^{\mathrm{a}}$ Perceptions of Brazilian journalists on privacy
}

\author{
ROGÉRIO CHRISTOFOLETTI ${ }^{\mathrm{b}}$
}

Universidade Federal de Santa Catarina, Programa de Pós-Graduação em Jornalismo. Florianópolis - SC, Brasil

\section{RESUMO}

Este artigo objetiva saber como os jornalistas brasileiros se relacionam com a privacidade em seu cotidiano profissional e como orientam suas condutas em dilemas éticos. Para isso, aplicamos uma pesquisa on-line para 120 jornalistas, questionando sobre suas condutas em apurações e divulgações. Os sujeitos da pesquisa são profissionais de redação, homens e mulheres, com diversas trajetórias e experiências, de todas as regiões do país. Os resultados sugerem que os jornalistas brasileiros valorizam mais a privacidade de suas fontes que as próprias, que existe um comportamento oscilante na divulgação de temas delicados como estupro, sequestro e suicídio e que há muitas incertezas em como agir diante de novas tecnologias, como o uso de drones.

Palavras-chave: Privacidade, jornalistas, reportagem, tecnologia, ética jornalística

\section{ABSTRACT}

This article aims to understand how Brazilian journalists relate to privacy in their profession and how they guide their behavior in ethical dilemmas. For this, an online survey was applied to 120 journalists questioning their conduct in investigations and disclosures. The research participants were writing professionals, with diverse trajectories and experience from all regions of the country. The results suggest that Brazilian journalists value the privacy of their sources more over their own, and that there is an oscillating behavior in spreading delicate topics such as rape, kidnapping and suicide. Also, many uncertainties were noted regarding how to act in the face of new technologies, such as the use of drones.

Keywords: Privacy, journalists, reporting, technology, media ethics

${ }^{\text {a }}$ Este artigo apresenta resultados parciais da pesquisa "Privacidade e Jornalismo: atualizações de conceitos, dilemas e entornos", financiada pelo Conselho Nacional de Desenvolvimento Científico e Tecnológico (CNPq).

${ }^{b}$ Docente do Departamento de Jornalismo da Universidade Federal de Santa Catarina (UFSC), onde é um dos coordenadores do Observatório da Ética Jornalística (objETHOS). Bolsista de produtividade do CNPq. Orcid: https://orcid.org/0000-00031065-4764. E-mail: rogerio. christofoletti@ufsc.br 


\section{Percepções de jornalistas brasileiros sobre privacidade}

\section{A PRIVACIDADE COMO QUESTÃO JORNALÍSTICA}

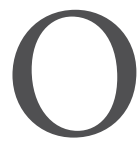

TEMA DA PRIVACIDADE tem uma larga zona de tensão ao seu redor, provocando choques entre direitos coletivos e individuais, dividindo a vida social contemporânea e permitindo redimensionamentos contínuos nos valores éticos (Miller, 1971; Garfinkel, 2000; Ribeiro, 2003).

Nas sociedades complexas atuais, existem situações nas quais as expectativas particulares tentam se sobrepor a aspirações de grupos, o que pode levar à supervalorização da esfera privada frente ao interesse público e a uma consequente opacidade informacional. Imagine-se, por exemplo, que ministros do Supremo Tribunal Federal do Brasil decidam que dados de suas remunerações funcionais não estejam mais acessíveis nos portais de transparência ou mesmo disponíveis para jornalistas. A justificativa poderia ser o resguardo da privacidade das autoridades do Poder Judiciário brasileiro. Com isso, a negativa da informação faria prevalecer os direitos individuais dos ministros, afrontando o direito coletivo à informação e provocando desconfiança generalizada sobre o repasse de recursos públicos à corte.

O exemplo ilustra uma clara colisão de direitos e, sobretudo, a frustração do que se entende por interesse público. Com a negativa da informação sobre os salários dos ministros, a transparência dos atos de governo fica comprometida, dificultando o acompanhamento desses movimentos pela sociedade.

Historicamente, o jornalismo justifica sua existência a partir da finalidade pública de atender às demandas de informação da sociedade (cf. Kovach \& Rosenstiel, 2003); à medida que informa, também contribui para a democracia e fortalece a cidadania. É esperado, portanto, que, para atender ao interesse público, o jornalismo colida com as expectativas de privacidade de pessoas, grupos e organizações. Assim, o tema da privacidade se apresenta constantemente no horizonte de preocupações éticas do jornalismo, sendo necessário revisitar suas bordas com frequência.

Como objeto de estudo, a privacidade tem uma dicotomia fundamental (privacidade-publicidade), mas é importante frisar que ela não é a única. Quando se observa o assunto pelas lentes do jornalismo, estão em jogo também debates sobre a confidencialidade de fontes, a segurança da informação e a proteção dos próprios jornalistas, para citar os mais imediatos vetores de discussão. Mais recentemente, também são vocalizados os eventuais impactos do direito ao esquecimento em coberturas jornalísticas e os cuidados nas políticas de privacidade de sites e plataformas para a captura e o uso de dados da audiência (Shapiro \& Rogers, 2016; Silveira, 2017; Pereira, 2018).

Se a privacidade já não é mais o que era antigamente (Rosenberg, 1969; Whitaker, 1999; O'Hara \& Shadbolt, 2008; Vincent, 2016), suas novas configurações também afetam uma atividade que tem na sua deontologia revelar segredos, 
expor pessoas, governos e corporações, além de violar espaços antes reservados para atender a uma demanda de conhecimento público. Diante de uma guerra contra a privacidade (Klosek, 2007) e a perspectiva de seu desaparecimento (Sykes, 1999; Tubaro, Casilli, \& Sarabi, 2014; Sarat, 2015), torna-se cada vez mais necessário redefinir suas fronteiras e natureza (Blatterer, Johnson, \& Markus, 2010), alcançando expectativas mais razoáveis de atendimento. Incapaz de garantir resguardo ou ocultamento, a privacidade passa a ser definida por seus contextos sociais (Nissenbaum, 2010), com fronteiras mais movediças e dialéticas (Petronio, 2002), mais pragmática (Solove, 2008) e derivada de dinâmicas negociações (Boyd, 2010).

Apesar da já demonstrada capacidade de vigilância massiva em tempo real por governos e corporações, da entrega espontânea de dados por seus titulares em troca de capital social e do crescente status da privacidade como bem de consumo (Peres-Neto, 2018), é exagerado afirmar que a privacidade não existe mais. $\mathrm{Na}$ atualidade, ela tem menos a ver com esconder coisas sobre si e mais sobre gerenciar as próprias informações (Mills, 2015; McStay, 2017), não significando que os esforços para preservar dados venham apenas de seus sujeitos. Isso deve ser preocupação de Estados, corporações e cidadãos, conforme se pode perceber na Declaração de Privacidade de Madri, de 2009, por exemplo.

Em maior ou menor grau, o tema da privacidade atravessa o jornalismo há três séculos (Hulteng, 1990; Karam, 1997; Keeble, 2001; Sanders, 2003; Plaisance, 2011; Christofoletti \& Torres, 2017) ${ }^{1}$. Em 1890, ela foi afirmada pela primeira vez como direito, a partir de um artigo de Warren e Brandeis (1890), por advogados preocupados com a impertinência das recentes câmeras fotográficas da imprensa. Ao longo do tempo, tornaram-se mais aperfeiçoados os instrumentos para violação da intimidade e cresceram os temores de eventuais abusos dos jornalistas que insistem em revelar segredos e inconveniências. A intromissão será tanto uma prática dos repórteres para obter informações quanto uma acusação de sua importunação.

Paulatinamente, os códigos deontológicos vão absorver preocupações sobre práticas lesivas e tentarão sinalizar limites profissionais, embora suas orientações sejam genéricas, superficiais e contraditórias (Allen, 2003; Christofoletti \& Gaia, 2018). Jornalistas dizem respeitar a vontade de suas fontes, mas violam a privacidade em várias situações. Gauthier (2002) enumera três modelos éticos que ajudam jornalistas a justificarem tais transgressões. Apesar disso, a autora esclarece que as invasões não podem ser rotineiras, devendo sempre estar sustentadas por persuasivos argumentos morais. Para Hodges (1994), jornalistas só devem contrariar a vontade de alguém quando a informação for de importância pública primordial e as demais pessoas não puderem saber por outros meios. Negar a alguém o controle dos seus círculos de intimidade é negar a medida da sua dignidade, adverte o autor. 


\section{Percepções de jornalistas brasileiros sobre privacidade}

Conforme Paul (1994), um dos paradoxos mais visíveis está no fato de que jornalistas revelam segredos alheios, mas não querem que se conheçam os seus e, assim, reagem mal quando o assunto é a própria privacidade. $\mathrm{O}$ mesmo se dá com as empresas de comunicação, sempre muito refratárias à transparência e à prestação de contas, embora lutem pelo fim da opacidade de governos e outras corporações. Schauer (2003) reconhece que as práticas jornalísticas vêm mudando ao longo do tempo, o que leva também as pessoas a alterarem suas expectativas dos espaços que podem guardar como reservados.

Outra dicotomia frequente é a que opõe privacidade à segurança, como se fosse necessário renunciar à primeira para garantir a segunda. Sumner (2016) contrapõe os argumentos dos setores que exploram a erosão da privacidade. Outros autores e organizações também rechaçam a premissa, contra-atacando com guias para reforçar a segurança pessoal e a privacidade de jornalistas (Antonialli \& Abreu, 2015; Fundación para la Libertad de Prensa, 2015; Moini, Ismail, \& Vialle, 2016; Dagan, 2017) e para fortalecer a privacidade das fontes e whistleblowers (Townend \& Danbury, 2016; Possetti, 2017). As revelações sobre vigilância global de Edward Snowden em 2013 têm modificado a relação entre jornalistas e fontes, conforme atesta Lashmar (2017), colocando em risco não só a privacidade, mas a própria democracia no ocidente.

Outra dificuldade atual para abordar a privacidade é equilibrar liberdade de imprensa e privacidade pessoal, já que "a definição de imprensa está se tornando efêmera", argumenta Mills (2015, p. 6). Se antes a privacidade era o direito de ser deixado em paz, hoje reivindica-se a capacidade de gerenciar as próprias informações (autonomia informacional). Segundo Mills (2015), até o anonimato mudou. Com as novas mídias, ele não permite só crimes e ações maléficas, mas em algumas circunstâncias também pode proteger a privacidade. Enquanto a livre expressão é princípio bem estabelecido nas democracias, a privacidade ainda não. Leis frágeis, limitação de responsabilidade dos provedores de internet e baixa expectativa de privacidade por parte da sociedade dificultam a defesa da intimidade pessoal (Rotenberg, 2016), sem contar que a tecnologia trouxe novas formas de intrusão, inéditas até então.

As mudanças tecnológicas são importantes, mas as culturais serão mais definidoras ainda, tanto para o enfrentamento de questões como anonimato e proteção de fontes, quanto para a segurança dos jornalistas diante de ameaças de vigilância estatal e espionagem (Carlson, 2012; Petley, 2013; Martins, 2013; Heikkilä, 2016).

Como a privacidade é compreendida pelos jornalistas na atualidade? Quais são suas condutas em relação à intimidade alheia ao apurarem informações? O que consideram importante revelar, mesmo contrariando a vontade de resguardo de terceiros? Buscamos, aqui, respostas a esses questionamentos no âmbito do jornalismo brasileiro, um dos maiores mercados produtores e consumidores de 
informação. Com 210 milhões de habitantes e mais de 150 milhões de usuários de internet (https://www.internetworldstats.com/), o Brasil tem uma indústria de mídia que movimentou mais de US\$ 35 bilhões em 2016, e pode chegar a US\$ 43,7 bilhões em 2021 ("No Brasil, setor", 2017). O mercado, muito concentrado, sofre forte influência política e religiosa e apresenta altos riscos à pluralidade e à diversidade de mídia (https://brazil.mom-rsf.org/). Entre os temas constantemente discutidos no jornalismo brasileiro, estão as formas intrusivas de obtenção de informação e a exposição exagerada e sensacionalista de pessoas e organizações.

Buscar compreender como os jornalistas brasileiros entendem privacidade e como agem nas situações em que ela é posta à prova são ações oportunas para aprofundar o tema.

\section{METODOLOGIA}

Para investigar as percepções de privacidade dos jornalistas brasileiros, recorremos a uma pesquisa on-line, aplicada somente a profissionais que atuam em redações. O questionário de 26 perguntas de múltipla escolha foi elaborado com ferramentas gratuitas do Google. Antes de ser distribuído aos respondentes, passou por quatro pré-testes para aperfeiçoamento e ajuste para um tempo médio de oito minutos de resposta (Apêndice A). Em janeiro de 2018, o questionário e o modelo do Termo de Consentimento Livre e Esclarecido (TCLE) foram submetidos à Plataforma Brasil (http://plataformabrasil.saude.gov.br/), base nacional de registros de pesquisas envolvendo seres humanos, mantida pelo Conselho Nacional de Ética em Pesquisa (Conep). Os documentos atenderam à Resolução $n^{\circ}$ 510/2016 do Conep e foram aprovados pelo Comitê de Ética em Pesquisa com Seres Humanos da Universidade Federal de Santa Catarina (http://cep.ufsc.br).

Foram garantidos aos participantes sigilo e anonimato, e foi esclarecido que os dados obtidos teriam apenas usos científicos. Foi ainda informado que a resposta ao questionário manifestaria o consentimento voluntário e não implicaria em nenhum pagamento ou vantagens adicionais. Os participantes foram alertados que, nos pré-testes realizados, não foram detectados danos psicológicos, físicos, laborais ou emocionais, mas algumas perguntas poderiam provocar eventuais desconfortos morais. Os participantes poderiam desistir da pesquisa e poderiam retirar seus consentimentos a qualquer momento.

O link do questionário foi distribuído manualmente a cada um dos membros de uma lista de jornalistas conhecidos, elaborada pelo pesquisador com base em outras listas eletrônicas profissionais de todo o país. A lista continha repórteres, editores, redatores, fotojornalistas e jornalistas de imagem. O convite para responder ao questionário encorajava os respondentes a distribuir o link para 
${ }^{2}$ Nesta etapa, o pesquisador teve apoio de diversos jornalistas e professores da área que encaminharam os convites para suas redes de contatos. Agradecemos a esses colaboradores. seus colegas de redação, o que permitiria a formação de uma amostra combinada a partir da conveniência e da técnica snowball sampling, não probabilística (cf. Goodman, 1961). Embora o objetivo não fosse operar sobre uma base amostral estatisticamente representativa do universo dos jornalistas em redação no Brasil, como fizeram Mick e Lima (2013), houve preocupação com a participação de profissionais de todas as regiões geográficas, com alguma proporcionalidade. Para assegurar isso, foi incluída na pesquisa uma questão para o respondente marcar sua localização, bem como outras que permitissem a observação de aspectos censitários. À medida que as respostas chegavam à base de dados, o pesquisador acompanhava a composição da amostra e disparava novos convites para as regiões menos participativas ${ }^{2}$. Embora as técnicas escolhidas não evitem completamente alguns vieses, os esforços para uma composição relativamente proporcional da amostra foram alcançados, conforme a Tabela 1.

\begin{tabular}{|c|c|c|}
\hline Região & Respondentes & Jornalistas por região \\
\hline Sul & $43,3 \%$ & 15,5 S\% \\
\hline Sudeste & $18,3 \%$ & $60,7 \AA \%$ \\
\hline Nordeste & $19,2 \%$ & $11,78 \%$ \\
\hline Norte & $10,8 \%$ & $11, \$ 6 \%$ \\
\hline Centro-Oeste & $\$, 4 \%$ & (contido acima) \\
\hline
\end{tabular}

Tabela 1. Amostra dos sujeitos de pesquisa comparados à presença de jornalistas no Brasil Fonte: Dados colhidos pelo autor; Mick e Lima (2013).

O questionário esteve disponível para preenchimento por dez dias, em junho de 2018, e foi respondido por 120 jornalistas brasileiros, a maioria deles homens $(53,3 \%)$. Em termos de trajetória, pouco mais de um quarto dos sujeitos da pesquisa é pouco experiente e tem menos de cinco anos de carreira (25,8\%), enquanto $15 \%$ são muito experientes e têm mais de vinte anos de jornalismo. Nos estratos intermediários, 35\% têm entre seis e dez anos, e 24,2\%, entre onze e vinte anos de profissão.

Em um terço dos casos, os respondentes atuam em mais de uma mídia, e $24,6 \%$ trabalham em veículos de internet. Outros 21,2\% operam em televisão; $19,5 \%$ em jornais; e menos de $2 \%$ em rádios e revistas. Da amostra, $38,7 \%$ se qualificam como repórteres; $20,2 \%$ são editores; e 14,3\% assumem outras funções. Em 21\% das respostas, os participantes marcaram a opção mais de uma das funções e, nos demais casos, eles se dividem entre redatores, produtores, repórteres cinematográficos e repórteres fotográficos.

A amostra observada é, portanto, ampla, geograficamente representativa, plural e diversificada no que se refere às plataformas de trabalho, às funções desempenhadas e ao tempo de experiência na profissão. Os resultados referentes à privacidade e aos seus entornos são apresentados a seguir. 


\section{RESULTADOS}

O questionário se estruturou em quatro seções, privilegiando o processo produtivo no jornalismo e suas condições intrínsecas. A primeira seção abordou aspectos gerais, com cinco questões indagando sobre conceitos de privacidade dos jornalistas. A seção seguinte era a mais extensa e continha nove perguntas sobre procedimentos e cuidados na apuração jornalística. A terceira parte do questionário propunha sete perguntas sobre as etapas de publicação e divulgação, enquanto a última seção reservava cinco questões para investigar aspectos ambientais das redações. O questionário na íntegra compõe o Apêndice A deste artigo.

\section{$\mathrm{O}$ que os jornalistas pensam sobre privacidade}

A primeira questão da pesquisa recorria a uma escala semântica crescente que ia de um (nada importante) a cinco (muito importante) e perguntava o que é a privacidade atualmente. Uma taxa expressiva de $60,8 \%$ das respostas foi muito importante, seguida de $24,2 \%$ de importante, ao passo que apenas $0,8 \%$ respondeu nada importante. A segunda pergunta era se jornalistas se preocupam com a privacidade de suas fontes. Para 48,3\%, a resposta foi $\operatorname{sim}$, enquanto para $46,7 \%$, às vezes. Responderam não 1,7\% dos participantes e 3,3\% não souberam opinar.

O questionário perguntou em seguida se os jornalistas se preocupavam com a própria privacidade; $60 \%$ das respostas foram às vezes, e $30 \%$ sim. Desta vez, o percentual de não alcançou 9,2\% das respostas (Tabela 2).

\begin{tabular}{|c|c|c|c|}
\hline \multicolumn{4}{|c|}{ Q2: Jornalistas se preocupam com a privacidade de suas fontes? } \\
\hline Sim & Não & Às vezes & Não sei opinar \\
\hline 4 S,3\% & $1,7 \%$ & $46,7 \%$ & $3,3 \%$ \\
\hline \multicolumn{4}{|c|}{ Q3: Jornalistas se preocupam com a própria privacidade? } \\
\hline Sim & Não & Âs vezes & Não sei opinar \\
\hline 30\% & $9,2 \%$ & $60 \%$ & $0, \$ \%$ \\
\hline
\end{tabular}

Tabela 2. Comparação entre preocupações com a privacidade alheia e com a própria

Fonte: Elaboração do autor.

Sobre o off-the-record, 59,2\% dos jornalistas brasileiros consideram-no uma prática comum e aceitável na profissão, seguidos de uma prática indispensável para jornalistas (24,2\%). Uma parcela de 3,3\% das respostas condenava a atitude como descartável, e 13,3\% afirmaram não saber responder.

Em relação à privacidade de pessoas famosas e ocupantes de cargos públicos, os jornalistas foram categóricos: quase dois terços (65\%) acham que deve haver menos privacidade para famosos que para pessoas comuns e 19,2\% assinalaram que não deve haver nenhuma privacidade para pessoas públicas. Um em cada oito respondentes pensa que a privacidade de famosos deve ser equivalente à de pessoas anônimas e apenas 3,3\% consideram que deve ser maior. 


\section{Apurando e obtendo informações}

A segunda seção do questionário se concentrava na etapa de apuração jornalística. Foi perguntado se jornalistas poderiam recorrer a bancos de dados não públicos para obter informações de terceiros. A maior parte dos jornalistas marcou opções afirmativas: $65,8 \%$ para sim, às vezes e sim, sempre, sinalizando uma predisposição intrusiva facilitada pela tecnologia. Apenas um sexto assinalou não, nunca (16,7\%), quase neutralizado pelas respostas mais reticentes: não sei $(15,8 \%)$ e indiferente (1,7\%), as quais, somadas, chegaram a $17,5 \%$.

Quanto à citação de e-mails de terceiros em reportagens, os jornalistas também parecem predispostos à invasão de privacidade: mais de dois terços concordam com o uso cotidiano sempre (10\%), desde que com autorização dos proprietários (30\%) ou com essa anuência e das pessoas mencionadas nas mensagens (27,5\%). Dentre os participantes, $26,7 \%$ se opõem a esse uso por considerar que se trata de comunicações privadas, e 5,8\% não souberam opinar. Quando indagados sobre a mesma permissividade, mas em relação a mensagens instantâneas de terceiros como as de WhatsApp -, a disposição de utilização de conteúdos privados em matérias é ainda maior. As alternativas sim alcançam $82,5 \%$ das respostas, enquanto os demais percentuais caem: não, 10,8\%, e não sei, 6,7\% (Tabela 3).

\begin{tabular}{|c|c|c|c|c|}
\hline \multicolumn{5}{|c|}{ Q6: Para fazer matérias, jornalistas podem recorrer a bancos de dados reservados para obter } \\
dados pessoais de alguém?
\end{tabular}

Tabela 3. Acesso e uso de conteúdos reservados por jornalistas

Fonte: Elaboração do autor.

A nona pergunta do questionário apresentava uma situação hipotética para que os jornalistas se posicionassem: um fotojornalista ou repórter cinematográfico usa um conjunto de lentes ou recursos técnicos para captar imagens de alguém numa propriedade privada (cf. Apêndice A). Metade das respostas demonstrou que os sujeitos discernem com clareza um crime de uma atitude 
antiética. Assim, 50,8\% marcaram a alternativa na qual o profissional estará invadindo a privacidade de alguém, mas não invadindo a propriedade. Uma parcela de $27,5 \%$ enxerga na cena crime e deslize ético, enquanto $17,5 \%$ dos jornalistas pensam que o profissional do exemplo estará usando recursos e técnicas aceitáveis jornalisticamente. Ficaram em dúvida 2,5\% e 1,7\% afirmaram que a situação revela crime de invasão de propriedade.

A questão seguinte explora situação semelhante, mas a partir do uso de drones para a captura de imagens. Desta vez, o discernimento entre invasão de propriedade e invasão de privacidade cai para $34,2 \%$. A consideração do cometimento de crime de invasão de propriedade e um deslize ético aumenta ligeiramente para 29,2\%, mas a fração que aceita o uso jornalístico dos drones nessa situação também sobe para 19,2\%. Dispara, no entanto, o percentual de sujeitos que não souberam opinar, chegando a $11,7 \%$, mais de quatro vezes a taxa anterior. Esse dado sugere a incerteza dos jornalistas sobre o uso dos drones como instrumento jornalístico.

Os jornalistas foram perguntados sobre o uso de câmeras ocultas para captar imagens de forma clandestina, e o panorama das respostas mostra a aceitação mesmo que velada - da prática. Na amostra, 54,2\% assinalaram que se trata de uma opção condenável na maioria das vezes, mas que pode ser usada em outras. Quase um quarto considera a prática uma opção útil para jornalistas (23,3\%), e 14,2\%, uma prática comum e aceitável para os jornalistas. Apenas 6,7\% se opõem ao uso de câmeras ocultas e 1,6\% não souberam responder. Esse quadro não se modificou muito quando os participantes foram indagados sobre o uso de celulares com microfones para captar áudio à distância e de modo furtivo: 55\% consideram uma opção condenável na maioria das vezes, mas que pode ser usada em outras; 31,7\% pensam ser uma opção útil para jornalistas; e 6,7\% uma prática comum e aceitável. Uma parcela de 5\% rechaça a prática e 1,6\% não soube responder.

Os dois questionamentos seguintes exploraram as redes sociais como ambientes em que podem ser obtidas informações para matérias jornalísticas. Em ambos os casos, a maior parte dos sujeitos parece considerar as redes sociais como espaços públicos, livres, e que independem do consentimento para o uso de conteúdo. Sobre o recolhimento de fotos de pessoas em redes sociais para ilustrar reportagens, quase metade dos jornalistas respondeu que a prática é completamente aceitável, já que as fotos estão em acesso público (48,3\%), mas 40\% diz ser aceitável desde que se tenha autorização da pessoa. Apenas 5,8\% recusam o procedimento porque sem a autorização da pessoa é invasão de privacidade, e 1,7\% não souberam responder. Dentre os jornalistas, 4,2\% são completamente permissivos, já que consideram o gesto indispensável e esperado.

Quando se trata da extração de imagens de pessoas mortas para ilustrar matérias, há comportamentos conflitantes: ao mesmo tempo em que é majoritária 
a permissividade no uso, já que estão em acesso público (42,5\%), dobrou o percentual de recusa, alcançando $11,7 \%$ da alternativa nunca, pois desrespeita a memória dos falecidos. Uma fatia de $41,7 \%$ condiciona o uso à autorização da família, e 4,1\% não sabem (Tabela 4).

\begin{tabular}{|c|c|c|c|c|}
\hline \multicolumn{5}{|c|}{ Q13: Recolher fotos de pessoas em redes sociais para ilustrar reportagens é... } \\
\hline $\begin{array}{c}\text {...inaceitável porque } \\
\text { sem autorização da } \\
\text { pessoa é invasão de } \\
\text { privacidade }\end{array}$ & $\begin{array}{c}\text {...completamente } \\
\text { aceitável, já que as } \\
\text { fotos estão em acesso } \\
\text { público }\end{array}$ & $\begin{array}{c}\text {... aceitável desde } \\
\text { que se tenha } \\
\text { autorização da } \\
\text { pessoa }\end{array}$ & $\begin{array}{c}\text {...indispensável } \\
\text { e esperado }\end{array}$ & Não sei \\
\hline $5,8 \%$ & $4 \mathrm{~S}, 3 \%$ & $40 \%$ & $4,2 \%$ & $1,7 \%$ \\
\hline \multicolumn{5}{|c|}{ Q14: Imagens de pessoas mortas podem ser retiradas de suas redes sociais para ilustrar matérias? } \\
\hline \multicolumn{2}{|c|}{ Sim, já que estão em acesso público } & $\begin{array}{c}\text { Talvez, mas } \\
\text { tem que haver } \\
\text { autorização da } \\
\text { família }\end{array}$ & $\begin{array}{l}\text { Nunca, pois } \\
\text { desrespeita a } \\
\text { memória dos } \\
\text { falecidos }\end{array}$ & Não sei \\
\hline \multicolumn{2}{|c|}{$42,5 \%$} & $41,7 \%$ & $11,7 \%$ & $4,2 \%$ \\
\hline
\end{tabular}

Tabela 4. Procedimentos em redes sociais

Fonte: Elaboração do autor.

Nas duas questões, os percentuais que exigem autorização dos proprietários são bem aproximados das parcelas de uso ilimitado, mas deve-se notar que as parcelas que aceitam o recolhimento e uso de imagens de pessoas nas redes sociais expressam o pensamento da maioria dos jornalistas. Isto é, a maior parte reconhece nos sites de redes sociais repositórios de conteúdos prontos e livres para serem colhidos.

\section{Publicando e divulgando}

A divulgação é uma etapa do processo jornalístico que também afeta a privacidade alheia. Quando questionados sobre a identificação de pessoas envolvidas em matérias com denúncias de corrupção política, os jornalistas brasileiros foram quase unânimes ao qualificar a atitude como aceitável (99,2\%). Em 68,9\% das respostas, foi marcada a opção totalmente aceitável e necessária e, em 30,3\%, aceitável em alguns casos. Nenhum respondente optou pela alternativa inaceitável e desnecessária, e apenas $0,8 \%$ mostrou-se indiferente. A adesão maciça ao gesto de identificar envolvidos em corrupção reforça um aspecto muito valorizado no cânone deontológico da profissão: o jornalismo deve denunciar os maus feitos, mesmo que esse gesto fira direitos individuais, como o da privacidade.

Porém, a opinião dos jornalistas se divide quando a reportagem trata de outros crimes, como assassinato, sequestro e estupro. Diferente da corrupção, esses são crimes contra a vida e têm, por isso, um elemento adicional importante: a vítima. O ímpeto dos jornalistas de divulgar maus feitos (ou crimes) 
permanece, conforme se pode ver nas respostas colhidas, mas os profissionais também consideram legítimo e aceitável identificar as vítimas.

Em matérias sobre homicídios e sequestros, as alternativas mais assinaladas pelos jornalistas foram justamente as que diziam que os nomes dos criminosos e das vítimas deveriam aparecer necessariamente: $42 \%$ e 28,6\%, respectivamente. Em ambas as perguntas, as segundas alternativas mais marcadas eram condicionantes: depende de quem for o acusado e a vítima, 26,9\% e 23,6\%. Na pergunta sobre assassinatos, 0,8\% marcaram depende de quem for o acusado e 1,7\% depende de quem for a vítima, e na questão sobre sequestros, $2,5 \%$ e 5\%, respectivamente, marcaram essas alternativas. Tais opções levam a pensar que os critérios para a decisão sobre o que se publica sobre crimes não são absolutamente rígidos, e podem variar conforme notoriedade, condição social ou outras características dos envolvidos. Se por um lado as redações não decidem automaticamente, por outro, cresce a margem de julgamentos pessoais ou potencialmente afetáveis por subjetividades ou outros fatores. Isso pode aumentar o enviesamento e a variação nos critérios editoriais para a exposição de pessoas em matérias. A pesquisa mostra, por exemplo, que o nome da vítima de assassinato deveria ser mais divulgado que o do criminoso (13,4\% contra $5 \%)$, situação que se inverte quando o crime é de sequestro (1,7\% contra 15,1\%).

Esse panorama se modifica sensivelmente quando o crime a ser reportado é o de estupro. Um terço dos respondentes considera que apenas a identidade do acusado deve ser divulgada (33,6\%), enquanto 3,4\% sinalizaram que os nomes tanto do criminoso quanto da vítima devem ser publicados. Não chegaram a 10\%, somadas, as três opções que diziam que dependia de quem fossem os envolvidos. Uma taxa de $0,8 \%$ dos jornalistas considerou que apenas a identidade da vítima precisaria ser conhecida pelo público. Mais de um quinto dos respondentes marcou que nenhum nome deveria aparecer na matéria (22,7\%), um índice de renúncia à publicação bem superior ao dos crimes anteriores, sinalizando um cuidado maior para evitar exposições desnecessárias ou exageradas.

Os dados revelam que, nesse tipo de crime, a vítima é mais preservada que em outras ocasiões, e essa opção se deu independentemente de sexo. Isoladas as respostas de homens e mulheres, verificou-se que as três respostas mais frequentes foram as mesmas (só o acusado, depende, ninguém), e que os percentuais de distribuição estão em faixas muito próximas. Nesse sentido, é possível afirmar que o gênero dos sujeitos da pesquisa não determinou as respostas. Mulheres e homens afirmaram ser mais necessário expor o acusado de estupro que a vítima, e um quarto dos homens e um quinto das mulheres optariam por não divulgar nenhuma identidade dos envolvidos. Uma razão para esta disposição talvez esteja relacionada à natureza do próprio crime. Diversos estigmas cercam o estupro, e a vítima sobrevivente, não raro, se vê julgada socialmente por sua condição. 
${ }^{3}$ A Organização Mundial da Saúde e a Associação Brasileira de Psiquiatria têm materiais que orientam os jornalistas a como

lidar com situações-limite a exemplo de estupros e suicídios.
Outro tema tabu é o suicídio, e os jornalistas foram indagados sobre o que deveria ser divulgado nesses casos. Quase um terço $(32,8 \%)$ rechaçou a possibilidade de publicação, marcando a opção nada, suicídios nunca devem ser noticiados, a maior taxa de renúncia registrada na pesquisa. Isso sinaliza que um em cada três jornalistas considera importante não só preservar a privacidade alheia nessas situações, mas também as circunstâncias que cercam o ato. Um pouco mais de um quarto da amostra cogita publicar algo, pois marcou a alternativa depende de quem for a vítima (25,2\%). Mas 28,2\% dos profissionais escolheram algum grau de exposição: Nome, idade e ocupação da vítima (19,3\%); Só a motivação do ato (4,2\%); Dados pessoais da vítima e a motivação do ato (1,7\%); Todas as anteriores e a "técnica" usada para o suicídio (1,7\%); Motivação do ato e a "técnica" (1,7\%). Ninguém marcou a opção de divulgar apenas a técnica do suicídio, e 13,4\% afirmaram não saber, o que aponta para um impasse de um para cada oito jornalistas na cobertura de casos desse tipo ${ }^{3}$ (Tabela 5).

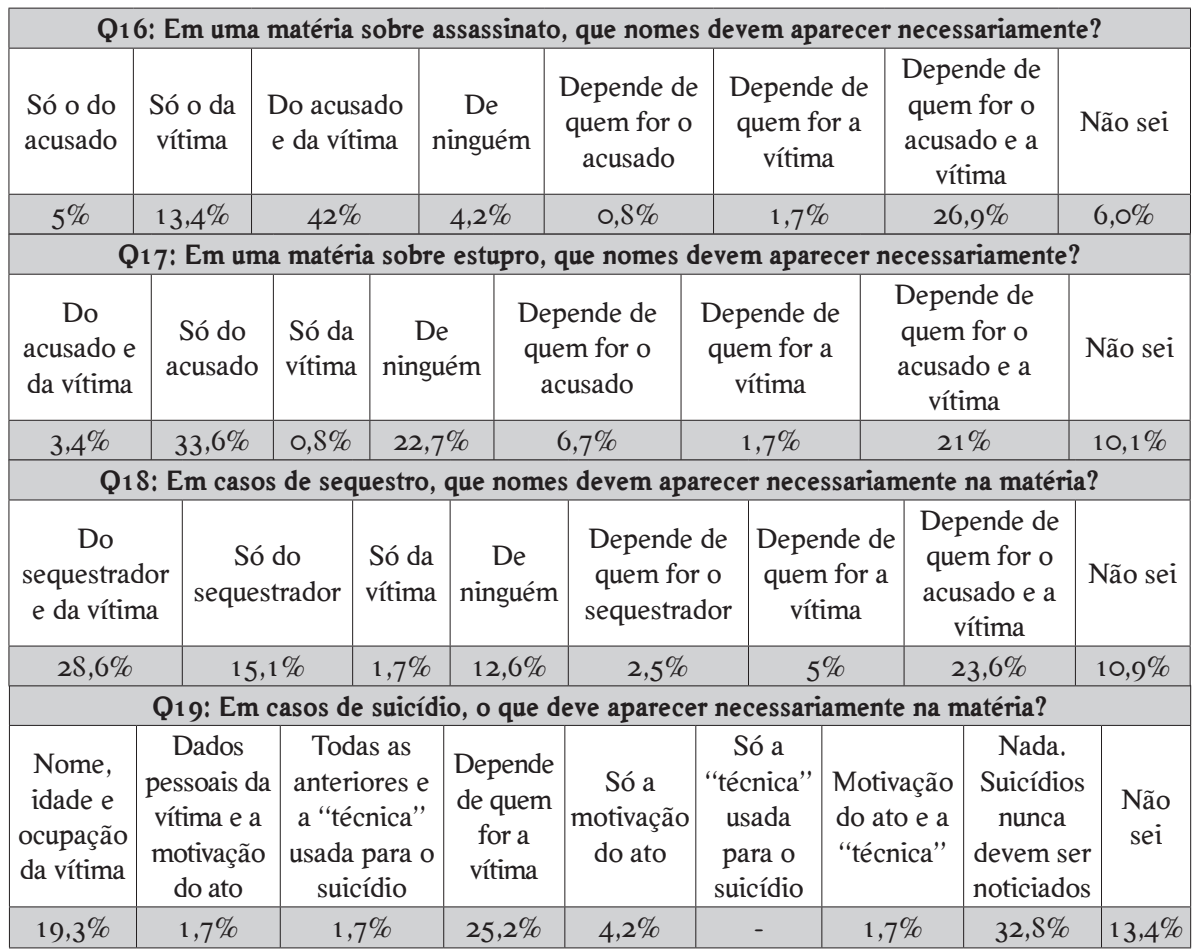

Tabela 5. Identificação de pessoas em crimes e situações delicadas Fonte: Elaboração do autor.

Sobre o sigilo de fonte, foi perguntado aos jornalistas em que circunstâncias ele deve ser mantido. O maior motivador da confidencialidade não é a vontade 
da fonte $(29,4 \%)$, mas os riscos que a publicação pode trazer para jornalistas e entrevistados, juntos ou separados $(68,1 \%)$.

A possibilidade de risco parece ser decisiva quando se trata de divulgar dados a partir de vazamentos. Para 39,2\% dos jornalistas brasileiros, deve-se evitar divulgar nomes, endereços e outros dados de pessoas mencionadas e para 25,8\%, é necessário garantir o anonimato das pessoas indicadas nos vazamentos e publicar o resto. A menor parcela de respostas (6,7\%) optou por segurar as informaçóes e não publicar nada dos vazamentos. No outro extremo, 8,3\% assinalaram divulgar todas as informações, mesmo que afetem pessoas envolvidas. Embora fugas de informação sejam cada vez mais frequentes e ajudem a alimentar o noticiário - como com WikiLeaks e Edward Snowden -, um quinto dos jornalistas respondeu não saber como agir em situações de vazamento.

\section{Aspectos ambientais}

Para além de suas concepções individuais, jornalistas podem viver em situações que estimulam ou desencorajam cuidados especiais para garantir a privacidade pessoal ou de terceiros. A estrutura da empresa na qual trabalha, culturas organizacionais e políticas internas são aspectos ambientais relevantes. Por isso, foi perguntado aos jornalistas se seus locais de trabalho tinham políticas editoriais para proteger a privacidade de fontes. A maior parte respondeu $\operatorname{sim}(45,7 \%)$, enquanto $10,4 \%$ disse não. Um percentual de $31,4 \%$ afirmou que sua empresa não tem políticas específicas, mas orienta os jornalistas a lidarem com o tema da privacidade, e 12,5\% disseram desconhecer se suas redações contam com tais políticas.

Embora haja organizações jornalísticas que invistam no tema, os resultados mostram que privacidade não é prioridade na mídia brasileira e nem preocupação hegemônica. Isso fica mais claro quando se indaga sobre orientações das empresas para a proteção dos próprios jornalistas. Embora 40,7\% tenham respondido afirmativamente e $3,7 \%$ tenham dito que suas empresas oferecem cursos sobre segurança digital, $42,6 \%$ dos jornalistas negaram receber orientações para proteger suas privacidades. Isto é, quatro em cada dez profissionais parecem estar descobertos e expostos a riscos, invasões e violações de intimidade. Este dado é corroborado pelas respostas à questão seguinte, a qual perguntava se a empresa favorecia o uso de ferramentas de criptografia e outras formas de segurança digital. Praticamente metade respondeu não (49,1\%), 12,8\% marcaram sim e 38,1\% afirmaram desconhecer (Tabela 6). 


\begin{tabular}{|c|c|c|c|c|}
\hline Sim & $\begin{array}{l}\text { Não } \\
\text { tem }\end{array}$ & $\begin{array}{c}\text { Não tem políticas específicas, } \\
\text { mas orienta os jornalistas a } \\
\text { lidarem com o tema }\end{array}$ & Desconheço & $\begin{array}{l}\text { Não se aplica, pois não } \\
\text { estou vinculado a uma } \\
\text { empresa }\end{array}$ \\
\hline $40 \%$ & $9,2 \%$ & $27,5 \%$ & $10,8 \%$ & $12,5 \%$ \\
\hline \multicolumn{5}{|c|}{ Q23: A empresa orienta os jornalistas a protegerem a própria privacidade? } \\
\hline $\begin{array}{l}\text { Não } \\
\text { sei }\end{array}$ & Sim & $\begin{array}{l}\text { Sim. A empresa inclusive oferece } \\
\text { cursos sobre segurança digital }\end{array}$ & Não & $\begin{array}{l}\text { Não se aplica, pois não estou } \\
\text { vinculado a uma empresa }\end{array}$ \\
\hline $11,7 \%$ & $36,7 \%$ & $3,3 \%$ & $3 S, 3 \%$ & $10 \%$ \\
\hline \multicolumn{5}{|c|}{ Q24: A empresa favorece uso de ferramentas de criptografia e outras formas de segurança digital? } \\
\hline Sim & Não & Desconheço & \multicolumn{2}{|c|}{$\begin{array}{c}\text { Não se aplica, pois não estou vinculado a } \\
\text { uma empresa }\end{array}$} \\
\hline $11,7 \%$ & $45 \%$ & $35 \%$ & & $8,3 \%$ \\
\hline
\end{tabular}

Tabela 6. Condições das organizações jornalísticas quanto à proteção da privacidade

Fonte: Elaboração do autor.

A desatenção com a privacidade parece não ser uma prerrogativa apenas empresarial. Jornalistas sentem necessidade de intensificar cuidados com a privacidade das fontes e pessoas mencionadas em suas matérias? Mais da metade das respostas discordou do enunciado ou se mostrou indiferente $(52,5 \%)$, revelando pouca disposição para aumentar os protocolos de segurança.

Por fim, foi questionado se os avanços tecnológicos das últimas décadas fizeram os jornalistas se preocuparem menos com a privacidade alheia. A maioria $(60,8 \%)$ concorda que possa haver uma correlação entre desenvolvimento, mudanças culturais e afrouxamento moral. Essa correspondência alcançou os maiores níveis entre os jornalistas com seis a dez anos de carreira $(71,4 \%)$ e com onze a vinte anos $(61,9 \%)$, justamente aqueles que viveram profundas transformações tecnológicas e culturais em suas trajetórias profissionais e têm sido levados a se adaptarem a elas. Para jornalistas menos ou mais experientes, as mudanças tecnológicas das últimas décadas não influenciaram muito na percepção profissional sobre a privacidade.

\section{CONSIDERAÇÕES FINAIS}

Jornalismo e privacidade têm um longo, difícil e paradoxal relacionamento, conforme atesta McStay (2017). Privacidade tem menos a ver com tecnologia e mais com direitos e convenções sociais que guiam as mais básicas interações coletivas, argumenta o autor. Neste sentido, privacidade não tem a ver com esconder ou se defender. Tem a ver com as formas de relacionamento, conexão e interação com os outros e como as pessoas controlam e gerenciam o acesso a si mesmas e àqueles de quem estão próximas. É o que se percebe pelas respostas dos jornalistas brasileiros no questionário aplicado. A adoção de tecnologias 
pode alterar alguns protocolos de sociabilidade com as fontes, por exemplo, mas não é o dispositivo em si que determina tais mudanças.

Diante do uso de drones para captação de imagens, os jornalistas brasileiros que responderam ao questionário consideram-no um instrumento legítimo no cotidiano. Apesar disso, demonstram dúvidas se a utilização incide em violação de privacidade ou invasão de propriedade. Isto é, os drones embaçam as fronteiras entre um deslize ético e um crime. Tal incerteza talvez seja decorrente da novidade do artefato, de seu uso ainda incipiente e do desconhecimento de seu funcionamento (alcance, autonomia de voo, recursos técnicos etc.). Assim, a paulatina adoção dos drones como artefatos de apuração jornalística e sua consequente apropriação pelas redações vai promover debates internos e a definição de padrões práticos. Repetimos: não é o equipamento (a tecnologia) que determina os parâmetros sobre privacidade, mas a sua absorção e uso (a cultura).

McStay (2017) sugere que privacidade seja, ao mesmo tempo, uma norma de comportamento social e um conjunto de expectativas escritas ou tácitas sobre como pessoas e organizações devem interagir. Em situações práticas, percebe-se agudamente quando elas deixam de existir ou quando as expectativas não foram atendidas. Assim, a privacidade não tem regras absolutas; é um fenômeno que surge a partir dos atores nas relações que estabelecem entre si. Daí poderem ser contraditórias e movediças. As normas de privacidade não vêm de fora, mas do protocolo que as pessoas convencionam. Em tempos de novas mídias, de crise do jornalismo e do império de plataformas como Facebook e Google, é preciso considerar a privacidade em rede, no qual ela é um processo ativo de gestão e negociação com pessoas e processos técnicos. Não é um ato pessoal, mas uma responsabilidade coletiva, conforme frisa McStay (2017).

Os dados desta pesquisa apontam para o fato de os jornalistas brasileiros valorizarem a privacidade e se importarem mais com a privacidade de suas fontes do que com a própria, o que é preocupante diante da crescente vigilância massiva e das perseguições de empresas e governos a jornalistas. Esse desequilíbrio potencializa as vulnerabilidades do jornalismo, que insiste em revelar segredos, escrutinar o poder e investigar maus feitos. Esse tipo de jornalismo parece ser o majoritário entre os brasileiros, já que $84,2 \%$ afirmaram não estar dispostos a deixar de perseguir famosos e detentores de cargos públicos.

Os resultados traçam um perfil impetuoso e até mesmo intrusivo dos jornalistas no Brasil. A maior parte deles não hesita em usar bancos de dados reservados para obter dados pessoais de alguém para fazer matérias, e apenas uma porção se recusaria a usar e-mails pessoais (26,5\%) e mensagens instantâneas $(10,8 \%)$ em reportagens. O comportamento geral é, portanto, mais invasivo, e acredita ser legítimo ignorar que a troca de e-mails ou mensagens são atividades interpessoais, 


\section{Percepções de jornalistas brasileiros sobre privacidade}

portanto, regidas por expectativas maiores de privacidade. Tal postura fica flagrante diante das redes sociais. A pesquisa sugere que, para os jornalistas brasileiros, as redes sociais funcionam como prateleiras abertas nas quais se pode pegar $\mathrm{o}$ que bem entender, uma espécie de domínio público que dispensa permissões ou autorizações. Assim, os conteúdos publicados pelos usuários das redes seriam automaticamente franqueados para qualquer uso, o que não é verdadeiro nem em termos legais. Quando um usuário aceita os termos e a política de privacidade de uma plataforma como o Facebook, não necessariamente está autorizando a qualquer site ou emissora de televisão do mundo reproduzir seus conteúdos. $\mathrm{O}$ consentimento não é extensivo, e o uso irrestrito de conteúdos gerados por usuários pode se revelar um perigo para a atividade jornalística: sem anuência de seus proprietários e sem as devidas checagens de informação, podem ser publicados dados incorretos, incompletos, enviesados e imprecisos.

A maioria dos jornalistas brasileiros também aceita e naturaliza o uso de câmeras ocultas e apenas uma parcela bem reduzida rechaça a prática $(6,7 \%)$. Em geral, os profissionais aceitam obter informações mediante acordos de confidencialidade com suas fontes, o que consagra o off-the-record na profissão, contestado por apenas um sexto dos participantes da pesquisa.

As respostas reforçam os cânones profissionais à medida que sobrevalorizam o direito de informação do público frente aos direitos individuais de privacidade e intimidade. Por isso, em situações delicadas, como a divulgação de assassinatos, estupros, sequestros e suicídios, alguns jornalistas revelam a necessidade de resguardar as identidades das vítimas, pois o contrário pode abrir brechas para a estigmatização ou para julgamentos morais condenatórios.

Os resultados permitem entrever alguma indisposição para obter autorização das fontes por parte dos jornalistas. Para atender às demandas informativas da sociedade, parece não ser necessário o consentimento para o uso de imagens pessoais ou dados particulares de outra natureza. Para fazer prevalecer o direito à informação, autorizações são esquecidas ou simplesmente ignoradas. É bem verdade que jornalistas não devem pedir anuências a todo momento, sob risco de negativas inviabilizarem ou impedirem seu trabalho. Por outro lado, a simples ideia de consentimento parece não constar das preocupações habituais dos jornalistas brasileiros. $\mathrm{Na}$ órbita de um objeto como a privacidade, esta é uma questão que não pode ser desprezada. $\mathbf{M}$

\section{REFERÊNCIAS}

Allen, A. L. (2003). Why journalists can’t protect privacy. In C. L. LaMay (Ed.), Journalism and the debate over privacy (pp. 69-87). Londres, Inglaterra: Lea. 
Antonialli, D., \& Abreu, J. de S. (2015). Vigilância das comunicações pelo estado brasileiro: E a proteção a direitos fundamentais. São Paulo, SP: Electronic Frontier Foundation; InterLab. Recuperado de https://bit.ly/2he8se4

Ariès, P., \& Duby, G. (Orgs.). (1990a). História da vida privada 1: Do Império Romano ao ano mil. São Paulo, SP: Companhia das Letras.

Ariès, P., \& Duby, G. (Orgs.). (1990b). História da vida privada 2: Da Europa Feudal à Renascença. São Paulo, SP: Companhia das Letras.

Ariès, P., \& Duby, G. (Orgs.). (1991a). História da vida privada 3: Da Renascença ao Século das Luzes. São Paulo, SP: Companhia das Letras.

Ariès, P., \& Duby, G. (Orgs.). (1991b). História da vida privada 4: Da Revolução Francesa à Primeira Guerra. São Paulo, SP: Companhia das Letras.

Ariès, P., \& Duby, G. (Orgs.). (1992). História da vida privada 5: Da Primeira Guerra a nossos dias. São Paulo, SP: Companhia das Letras.

Blatterer, H., Johnson, P., \& Markus, M. R. (2010). Modern privacy: Shifting boundaries, new forms. Londres, Inglaterra: Palgrave Macmillan.

Boyd, D. (2010, março). Privacy, publicity, and visibility. Artigo apresentado na Microsoft Tech Fest. Microsoft: Redmond, DC. Recuperado de http://bit.ly/2lWhDWl

Carlson, M. (2012). On the condition of anonymity: Unnamed sources and the battle for journalism. Urbana-Chicago-Springfield, IL: University of Illinois Press.

Christofoletti, R., \& Gaia, G. O. (2018). Direito e proteção à privacidade em códigos deontológicos de jornalismo. Media e Jornalismo, 18(32), 43-54. Recuperado de https://impactum-journals.uc.pt/mj/article/view/5675

Christofoletti, R., \& Torres, R. J. (2017, março). La evolución de la privacidad en las guías de ética periodística. Artigo apresentado na $4^{\text {a }}$ International Conference On Media Ethics, Sevilla, Espanha.

Dagan, M. (2017). Online privacy for journalists: A must-have guide for journalism in 2017. Recuperado de http://bit.ly/2komEX6

Federação Nacional dos Jornalistas (2007). Código de Ética dos Jornalistas Brasileiros. Recuperado de https://bit.ly/2MtCPPM

Fundación para la Libertad de Prensa. (2015). Manual antiespías: Herramientas para la protección digital de periodistas. Recuperado de https://bit.ly/2Uvz3c1

Garfinkel, S. (2000). Database Nation: The death of privacy in the 21st century. Sebastopol, CA: O’Reilly.

Gauthier, C.C. (2002). Privacy invasion by the news media: three ethical models. Journal of Mass Media Ethics, 17(1), 20-34. doi: 10.1207/ S15327728JMME1701_03

Goodman, L. (1961). Snowball sampling. Annals of Mathematical Statistics, 32(1), 148-170. doi: 10.1214/aoms/1177705148

Heikkilä, H. (2016). Canaries in the Coalmine: Why journalists should be concerned by privacy. In U. Carlsson (Ed.), Freedom of expression and media in transition: Studies and reflections in the digital age (pp. 101-106). Gotemburgo, Suécia: Nordicom. 
Hodges, L. (1994). The journalist and privacy. Journal of Mass Media Ethics, 9(4), 197-212. doi: 10.1207/s15327728jmme0904_1

Hulteng, J. (1990). Os desafios da comunicação: Problemas éticos. Florianópolis, SC: Editora da UFSC.

Karam, F. J. C. (1997). Jornalismo, ética e liberdade. São Paulo, SP: Summus.

Keeble, R. (2001). Ethics for journalists. Londres, Inglaterra/Nova York, NY: Routledge.

Klosek, J. (2007). The war on privacy. Westport-Londres, Inglaterra: Praeger.

Kovach, B., Rosenstiel, T. (2003). Os elementos do jornalismo: O que os jornalistas devem saber e o público exigir. São Paulo, SP: Geração.

Lashmar, P. (2016). No more sources? The impact of Snowden's revelations on journalists and their confidential sources. Journalism Practice, 11(6), 665688. doi: 10.1080/17512786.2016.1179587

Martins, P. (2013). O privado em público (Tese de doutorado). Universidade Técnica de Lisboa, Lisboa.

McStay, A. (2017). Privacy and the media. Los Angeles, CA/Londres, Inglaterra: Sage.

Mick, J., \& Lima, S. (2013). Perfil do jornalista brasileiro: Características demográficas, políticas e do trabalho jornalístico em 2012. Florianópolis, SC: Insular.

Miller, A. R. (1971). The assault of privacy: Computers, data banks, and dossiers. Ann Arbor, MI: University of Michigan Press.

Mills, J. (2015). Privacy in the new media age. Miami, FL: University Press of Florida.

Moini, R., Ismail, B., \& Vialle, E. (2016). Censura e vigilância de jornalistas: Um negócio sem escrúpulos. Rio de Janeiro, RJ: Repórteres Sem Fronteiras.

Nissenbaum, H. (2010). Privacy in context: Technology, policy, and the integrity of social life. Stanford, CA: Stanford University Press.

No Brasil, setor deverá gerar receita de US\$43,7 bilhões em 2021, revela estudo da PwC (2017, 7 de junho). Pwc Brasil. Recuperado de https://pwc.to/2KqMSn0

O'Hara, K., \& Shadbolt, N. (2008). The spy in the coffee machine: The end of privacy as we know it. Oxford, Inglaterra: Oneworld.

Paul, N. (1994). Some paradoxes of privacy. In J. Black (Ed.), Privacy II: Exploring questions of media morality: A special issue of the Journal of Mass Media Ethics (pp. 228-230). Nova Jersey, EUA: Lea.

Pereira, M. (2018). A ética nas profundezas do mar sem-fim: As políticas de privacidade e a estratégia da ponta do iceberg no Facebook. In L. Peres-Neto, \& J. B. Corral (Orgs.), Éticas em rede: Políticas de privacidade e moralidades públicas (2a ed., pp. 168-179). São Paulo, SP: Estação das Letras e Cores.

Peres-Neto, L. (2018). Éticas, comunicação e consumo: Um mapa para pensar os desafios da privacidade em rede. In L. Peres-Neto, \& J. B. Corral (Orgs.), Éticas em rede: Políticas de privacidade e moralidades públicas (2a ed., pp. 10-34). São Paulo, SP: Estação das Letras e Cores.

Petley, J. (2013). Media and public shaming: Drawing the boundaries of disclosure. Londres, Inglaterra: I.B. Tauris.

Petronio, S. (2002). Boundaries of privacy: Dialectics of disclosure. Albany, NY: Suny. 
Plaisance, P. L. (2011). Ética na comunicação: Princípios para uma prática responsável. Porto Alegre, RS: Penso.

Possetti, J. (2017). Protecting journalism sources in the digital age. Paris, França: Unesco. Resolução No. 510, de 7 de abril de 2016 (2016, 24 de maio). Dispõe sobre as normas aplicáveis a pesquisas em Ciências Humanas e Sociais. Diário Oficial da União, seção 1. Recuperado de http://bit.ly/2lsUjiy

Ribeiro, D. V. H. (2003). Proteção da privacidade. São Leopoldo, RS: Editora Unisinos. Rosenberg, J. M. (1969). The death of privacy. Nova York, NY: Random House. Rotenberg, M. (2016). The privacy law sourcebook 2016. Washington, DC: Eletronic Privacy Information Center.

Sanders, K. (2003). Ethics and journalism. Thousand Oaks, CA: Sage.

Sarat, A. (Ed.). (2015). A world without privacy: What law can and should do? Nova York, NY: Cambridge University Press.

Schauer, F. (2003). The social construction of privacy. In C. L. LaMay (Ed.), Journalism and the debate over privacy (pp. 3-16). Londres, Inglaterra: Lea.

Shapiro, I., \& Rogers, B. M. (2016). How the "right to be forgotten" challenges journalistic principles. Digital Journalism, 5(9), 1101-1115. doi: 10.1080/21670811.2016.1239545

Silveira, S. A. (2017). Tudo sobre tod@s: Redes digitais, privacidade e comércio de dados. São Paulo, SP: Sesc Edições.

Solove, D. J. (2008). Understanding privacy. Cambridge, MA: Harvard University Press.

Sumner, S. (2016). You: For sale: Protecting your personal data and privacy online. Waltham, MA: Elsevier.

Sykes, C. J. (1999). The end of privacy: The attack on personal rights at home, at work, on-line, and in court. Nova York, NY: Saint-Martin Press.

The Public Voice (2009, 3 de novembro). The Madrid privacy declaration: Global privacy standards for a global world. Artigo apresentado na International Conference of Data Protection and Privacy Commissioners, Madrid, Espanha. Recuperado de http://thepublicvoice.org/madrid-declaration/

Townend, J., \& Danbury, R. (2016). Protecting sources and whistleblowers in a digital age. Londres. Inglaterra: Information Law and Policy Centre/Institute of Advanced Legal Studies. doi: 10.2139/ssrn.2961911

Tubaro, P., Casilli, A. A., \& Sarabi, Y. (2014). Against the hypothesis of the end of privacy: An agent-based modelling approach to social media. Londres, Inglaterra/Nova York, NY: Springer.

Vincent, D. (2016). Privacy: a short history. Cambridge, MA: Polity Press.

Warren, S. D., \& Brandeis, L. D. (1890). The right to privacy. Harvard Law Review, 4(5), 193-220.

Whitaker, R. (1999). The end of privacy: How total surveillance is becoming a reality. Nova York, NY: The New Press.

Artigo recebido em 4 de novembro de 2018 e aprovado em 26 de março de 2019. 


\section{APÊNDICE A \\ Questionário Aplicado}

Informações iniciais

Quanto tempo você tem de jornalismo?

( ) Menos de 5 anos de carreira ( ) 6 a 10 anos ( ) 11 a 20 anos ( ) Mais de 20 anos de carreira

Qual o seu sexo?

( ) Feminino ( ) Masculino ( ) Outros

Em que região brasileira você trabalha?

( ) Sul ( ) Norte ( ) Centro-oeste ( ) Nordeste ( ) Sudeste

Em que tipo de mídia você trabalha?

（ )TV ( ) Rádio ( ) Jornal （ ）Revista （） Internet ( ) Mais de uma das opções

Que função você desempenha atualmente?

( ) Repórter ( ) Redator/Redatora ( ) Editor/Editora ( ) Repórter Fotográfico(a)

( ) Repórter Cinematográfico(a) ( ) Produtor/Produtora ( ) Mais de uma das funções ( ) Outra

\section{Aspectos gerais}

1. Hoje em dia, a privacidade é...

Nada importante $<<<(\quad) 1$ ( ) 2 ( ) 3 ( ) 4 ( ) 5 >>> Muito Importante

2. Jornalistas se preocupam com a privacidade de suas fontes?

( ) Sim ( ) Não ( ) Às vezes ( ) Não sei opinar

3. Jornalistas se preocupam com a própria privacidade?

( ) Sim ( ) Não ( ) Às vezes ( ) Não sei opinar

\section{Jornalistas em geral consideram o off-the-record...}

( ) Uma prática comum e aceitável na profissão ( ) Uma prática inaceitável no jornalismo

( ) Uma prática indispensável para os jornalistas ( ) Uma prática descartável na profissão （ ） Não sei 
5. Como jornalistas em geral consideram o direito à privacidade de celebridades e pessoas com cargos públicos?

( ) Igual à de pessoas comuns e anônimas ( ) Menos privacidade para famosos que para pessoas comuns ( ) Maior privacidade, já que são mais importantes e servem de modelo para os outros ( ) Nenhuma privacidade para pessoas públicas ( ) Não sei

\section{Apurando e obtendo informações}

6. Para fazer matérias, jornalistas podem recorrer a bancos de dados reservados para obter dados pessoais de alguém?

( ) Sim, sempre ( ) Sim, às vezes （ ) Não, nunca （） Não sei （） Indiferente

\section{Jornalistas podem citar e-mails pessoais de terceiros em reportagens?}

( ) Sim, sempre ( ) Sim, desde que com autorização dos proprietários （ ） Sim, desde que haja autorização dos proprietários e das pessoas mencionadas nas mensagens ( ) Não, pois são comunicações privadas （ ） Não sei

\section{Jornalistas podem citar mensagens de WhatsApp de terceiros em reportagens?}

( ) Sim, sempre ( ) Sim, desde que com autorização dos proprietários ( ) Sim, desde que haja autorização dos proprietários e das pessoas mencionadas nas mensagens ( ) Não, pois são comunicações privadas （ ） Não sei

9. Se um fotojornalista ou repórter cinematográfico usar um conjunto de lentes ou recursos técnicos para captar imagens de alguém numa propriedade privada... ( ) ... ele estará cometendo um crime por invadir o terreno de alheio ( ）... ele

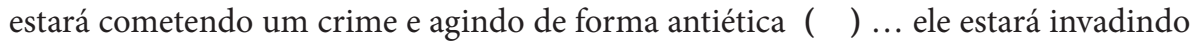
a privacidade de alguém, mas não invadindo a propriedade $($ )... ele estará usando recursos e técnicas aceitáveis jornalisticamente ( ) Não sei

10. Se um repórter cinematográfico usar um drone para captar imagens...

( ) ... ele estará cometendo um crime por invadir o terreno de alheio ( ) ... ele

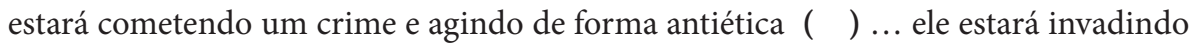
a privacidade de alguém, mas não invadindo a propriedade $(\quad$ ) ... ele estará usando recursos e técnicas aceitáveis jornalisticamente ( ) Não sei

11. O uso de câmeras ocultas para captar imagens de forma clandestina é...

( ) ... uma prática comum e aceitável para os jornalistas ( ）... uma prática inaceitável para se fazer jornalismo $(\quad$ )... uma prática indispensável para os jornalistas $(\quad$ )... 
uma opção útil para jornalistas ( ）... uma opção condenável na maioria das vezes, mas que pode ser usada em outras ( ) Não sei

12. Usar celulares com microfones muito sensíveis para captar áudio a distância e furtivamente é...

( ) ... uma prática comum e aceitável para os jornalistas $($ ) ... uma prática inaceitável para se fazer jornalismo ( ）... uma prática indispensável para os jornalistas ( ) ... uma opção útil para jornalistas （）... uma opção condenável na maioria das vezes, mas que pode ser usada em outras ( ) Não sei

13. Recolher fotos de pessoas em redes sociais para ilustrar reportagens é...

( ) ... inaceitável, porque sem a autorização da pessoa é invasão de privacidade

( ) ... completamente aceitável, já que as fotos estão em acesso público ( ) ... aceitável desde que se tenha autorização da pessoa $(\quad$ ) ... indispensável e esperado ( ) Não sei

14. Imagens de pessoas mortas podem ser retiradas de suas redes sociais para ilustrar matérias?

( ) Sim, já que estão em acesso público ( ) Talvez, mas tem que haver autorização da família

( ) Nunca, pois desrespeita a memória dos falecidos ( ) Não sei

\section{Publicando e divulgando}

15. Imagine uma reportagem com denúncias de corrupção política. A identificação dos envolvidos é...

（ ） Totalmente aceitável e necessária（） Aceitável em alguns casos（） Inaceitável e desnecessária ( ) Indiferente ( ) Não sei

16. Em uma matéria sobre assassinato, que nomes devem necessariamente aparecer?

（ ) Só o do acusado（）Só o da vítima（）Do acusado e da vítima（）De ninguém

( ) Depende de quem for o acusado ( ) Depende de quem for a vítima ( ) Depende de quem for o acusado e a vítima ( ) Não sei

17. Em uma matéria sobre estupro, que nomes devem necessariamente aparecer?

（ ) Só o do acusado （ ) Só o da vítima（）Do acusado e da vítima（）De ninguém

( ) Depende de quem for o acusado ( ) Depende de quem for a vítima

( ) Depende de quem for o acusado e a vítima ( ) Não sei 
18. Em casos de sequestro, que nomes devem necessariamente aparecer na matéria? （ ) Só o do acusado （ ) Só o da vítima（）Do acusado e da vítima（） De ninguém

( ) Depende de quem for o acusado ( ) Depende de quem for a vítima

( ) Depende de quem for o acusado e a vítima ( ) Não sei

\section{Em casos de suicídio, o que deve necessariamente aparecer na matéria?}

( ) Nome, idade e ocupação da vítima ( ) Dados pessoais da vítima e a motivação do ato ( ) Todas as anteriores e a "técnica" usada para o suicídio ( ) Depende de quem for a vítima ( ) Só a motivação do ato ( ) Só a "técnica" usada para o suicídio ( ) Motivação do ato e a "técnica" ( ) Nada. Suicídios nunca devem ser noticiados ( ) Não sei

20. De maneira geral, a identidade da fonte deve ser mantida em segredo...

( ) ... quando ela pedir ( ) ... quando sua divulgação implicar algum risco para a fonte ( ) ... quando sua divulgação implicar algum risco para o jornalista ( ）... quando houver risco para a fonte e para o jornalista ( ) ... Nunca ( ) Não sei

\section{Em vazamentos de informação, jornalistas devem...}

( ) ... evitar divulgar nomes, endereços e outros dados de pessoas mencionadas

( ) ... divulgar todas as informações, mesmo que afetem pessoas envolvidas

( ) ... garantir o anonimato das pessoas indicadas nos vazamentos e publicar o resto

( ) ... segurar as informações e não publicar nada dos vazamentos ( ) Não sei

\section{Aspectos ambientais}

22. A empresa onde você trabalha tem políticas editoriais para proteger a privacidade de fontes?

( ) Sim ( ) Não tem ( ) Não tem políticas específicas, mas orienta os jornalistas a lidarem com o tema ( ) Desconheço ( ) Não se aplica, pois não estou vinculado a uma empresa

\section{A empresa orienta os jornalistas a protegerem a própria privacidade?}

( ) Não sei ( ) Sim ( ) Sim. A empresa inclusive oferece cursos sobre segurança digital （ ） Não （ ） Não se aplica, pois não estou vinculado a uma empresa

24. A empresa favorece o uso de ferramentas de criptografia e outras formas de segurança digital pelos jornalistas?

( ) Sim ( ) Não ( ) Desconheço （） Não se aplica, pois não estou vinculado a uma empresa 
25. Jornalistas sentem necessidade de intensificar cuidados com a privacidade das fontes e pessoas mencionados.

Concordo totalmente $<<<(\quad) 1$ ( ) 2 ( ) 3 ( ) 4 ( ) 5 >>> Discordo totalmente

26. Os avanços tecnológicos das últimas décadas fizeram com que os jornalistas se preocupassem menos com a privacidade alheia.

Concordo totalmente $<<<(\quad) 1$ ( ) 2 ( ) 3 ( ) 4 ( ) $5>>>$ Discordo totalmente 